\title{
Hodgkin's disease presenting as idiopathic thrombocytopenic purpura
}

\author{
W. G. MURPHY \\ M.B., M.R.C.P. (U.K.) \\ D. J. PERRY \\ B.S.c., M.B., M.R.C.P. (U.K.)
}

\author{
N. C. Allan \\ F.R.C.P., Ed., F.R.C.Path. \\ G. STOCKDILL \\ M.B., M.R.C.P. (U.K.), M.R.C.Path.
}

Department of Haematology, Western General Hospital, Edinburgh EH4 $2 X U$

\begin{abstract}
Summary
A case of Hodgkin's disease presenting as idiopathic thrombocytopenic purpura in a 23-year-old male is reported. This is a rare presentation of Hodgkin's disease having been previously described in only two cases.
\end{abstract}

KEY WORDS: Hodgkin's disease, idiopathic thrombocytopenic purpura.

\section{Introduction}

Idiopathic thrombocytopenic purpura (ITP) may be the initial manifestation of systemic lupus erythematosus, lymphoproliferative disorder, or Evan's syndrome. The possibility of an associated or underlying pathological process should be borne in mind in cases of ITP, although it may be months or years before the true nature of the primary disease is revealed.

A case is presented in which an unsuspected diagnosis of Hodgkins's disease was made following splenectomy for ITP.

\section{Case report}

A 23-year-old engineer presented to his general practitioner in July 1982 with a 7-day history of a purpuric rash and gingival bleeding. Some 4 weeks earlier he had had an upper respiratory tract infection. He took little alcohol and had taken no drugs in recent months. On examination there was purpura on the legs, soft palate and gums but no other abnormality was detected. A full blood count showed a haemoglobin $14 \mathrm{~g} / \mathrm{dl}$, leucocyte count $8 \times 10^{9} /$ litre, and platelets $6 \times 10^{9} /$ litre. A bone marrow aspirate was consistent with idiopathic thrombocytopaenic purpura with increased numbers of megakaryocytes and defective platelet budding. Viral titres showed no evidence of recent infection. Anti-DNA titres and rheumatoid factor were negative. The patient was treated with oral prednisolone. His platelet coun $\vec{e}$ returned to normal and steroid therapy was tailed of and stopped after 3 months.

Three months later he relapsed with platelets of $6 \times 10^{9} /$ litre and recurrence of his symptoms. Prednio solone was restarted at $60 \mathrm{mg} /$ day with a view to raising the platelets before elective splenectomy. One week later he was found to be unrousable woth evidence of having vomited blood in his sleeppe Subsequently he had a grand mal fit and respiratöry arrest. Following resuscitation he had repeated hare matemeses and melaena - he remained drowsy with brisk reflexes and bilateral extensor plantars. Com puterized axial tomography (CT scan) revealed a lefg frontal haematoma without evidence of mid-lin shift. Emergency splenectomy was performed with platelet infusion following clamping of the splenie pedicle. The patient made a good recovery-platelet count rose rapidly to normal and has remained se since. There was no subsequent neurological abnor mality and follow-up CT scan showed resolution og the haematoma.

Histological examination of the spleen showe evidence of mixed-cellularity Hodgkin's disease, 8 diagnosis hitherto unsuspected. A CT scanning of the abdomen showed bilateral para-aortic disease and bipedal lymphography confirmed extensive para aortic lymph node involvement. A bone marrowo aspiration and trephine showed no evidence of lymphomatous infiltration but a bone scintogranos demonstrated widespread disease. No evidence of Hodgkin's disease above the diaphragm was found N The patient was staged as IV A according to the An?
Arbor classification (Carbone et al., 1971).

An alternating regime of chlorambucil, vinblase tine, prednisolone procarbazine (Chl.V.P.P.) an adriamycin, bleomycin, vinblastine and DTIC (A.B.V.D.) was commenced (Bonnadonna et al.] 
1982) and a complete remission obtained. The patient remains well to date.

\section{Discussion}

The concurrence of autoimmune disorders with lymphoproliferative disorders is well recognized (Jones, 1973), particularly in association with chronic lymphatic leukaemia. In Hodgkin's disease autoimmune haemolytic anaemia is uncommon and has been reported as occurring in $2.7 \%$ of cases in one large series (Eisner, Ley and Mayer, 1967). Thrombocytopenia appears to be a very unusual complication. Twenty-eight cases have been previously described (Cohen, 1978; Fink and Al-Mondhiry, 1976; Rudders, 1974; Paz, Bolo and Sanabria, 1980; Kirshner, Zamkoff and Gottlieb, 1980). In only two of these cases, however, (Rudders, Aisenberg and Schiller, 1972; Paz et al., 1980) did the diagnosis of ITP precede that of Hodgkin's disease.

It is not clear whether the association of ITP and Hodgkin's disease has an adverse effect upon the outcome (Cohen, 1978; Fink and Al-Mondhiry, 1976). The association has been described in all histological types of Hodgkin's disease and in all clinical and pathological stages.

This case serves as a reminder that spleens removed in the treatment of ITP should always be submitted for careful histological analysis.

\section{References}

Bonnadonna, G., Santoro, A., Bonfante, V. \& Valagussa, B.S. (1982) Alternating drug combinations is the treatment of advanced Hodgkin's disease. New England Journal of Medicine, 306, 770.

Carbone, P.P., Kaplan, H.S., Musshoff, K., Smithers, D.W. \& Tubiane, M. (1971) Report of the committee on Hodgkin's disease staging classifications. Cancer Research, 31, 1860.

COHEN, J.R. (1978) Idiopathic thrombocytopenic purpura in Hodgkin's disease. A rare occurrence of no prognostic significance. Cancer, $41,743$.

EISNER, E., LEY, A.B. \& MAYER, K. (1967) Coombs' positive hemolytic anemias in Hodgkin's disease. Annals of Internal Medicine, 66, 258.

FINK, K. \& AL-MONDHIRY, H. (1976) Idiopathic thrombocytopenic purpura in lymphoma. Cancer, 31, 1999.

JONES, S.E. (1973) Autoimmune disorders and malignant disorders. Cancer, 31, 1092.

KIRSHNeR, J.J., ZAMKofF, K.W. \& GotTlieb, A.J. (1980) Idiopathic thrombocytopenic purpura and Hodgkin's disease: report of two cases and review of the literature. American Journal of the Medical Sciences, $280,21$.

Paz, R.A., Bolo, H. \& Sanabria, A. (1980) Purpura thrombocitopenica idiopatica come manifestation inicial de una enfermedad de Hodgkin. Medicina (Buenos Aires), 40, 176.

RUDDERS, R.A. (1974) Autoimmune thrombocytopenic purpura in Hodgkin's disease. Cancer, 30, 220.

Rudders, R.A., AisenberG, A.C. \& Schiller, A.L. (1972) Hodgkin's disease presenting as idiopathic thrombocytopenic purpura. Cancer, 30, 220.

(Accepted 6 September 1983) 